\title{
Establishing Human Liver Cell Models to Investigate the Effects of Exogenous Metabolic Substrates on Fatty Acid Partitioning
}

\section{Introduction}

- Hepatic steatosis, accumulation of intracellular triglyceride (TG) (> 5\% of hepatic tissue), is the prerequisite for the development of non-alcoholic fatty liver disease (NAFLD).

- NAFLD is associated with obesity and obesity-related metabolic diseases.

- Steatosis occurs due to an imbalance between fatty acid input and removal (fatty acid partitioning) which may be influenced by genetics, diet, hormones and drugs; making the cause of NAFLD difficult to elucidate.

- Hepatocyte cell models that represent fatty acid partitioning within the human liver would be beneficial for the study of the development and progression of NAFLD.

OBJECTIVE: we used a well characterised human liver cell line (LIVOAPOLY) and human primary hepatocytes to investigate the effect of specific nutrients (glucose, fructose and fatty acids) on hepatic lipid metabolism

\section{Methods}

- LIVOAPOLY cells were grown for $48 \mathrm{~h}$ on low-glucose (LG, $5.5 \mathrm{mM}$ ) or high-glucose (HG, $22.5 \mathrm{mM}$ ) DMEM. Primary human hepatocytes cultured for $24 \mathrm{hrs}$ ( $11 \mathrm{mM}$ glucose).

- Cells were treated with $0.25 \%$ fatty acid-free BSA alone or conjugated to $49.5 \mu \mathrm{M}$ oleic, $33 \mu \mathrm{M}$ palmitic, and $27.5 \mu \mathrm{M}$ linoleic acid (OPL; physiological ratio 45:30:25\%).

- Palmitate was labelled $\left[50 \% \mathrm{D}_{31}, 50 \% \mathrm{U}-{ }^{13} \mathrm{C}\right]$ for $24 \mathrm{~h}$.

- Cells and media were collected for analysis by GC-Ms and biochemical analyser

Effects of high glucose on lipid portioning and cell health
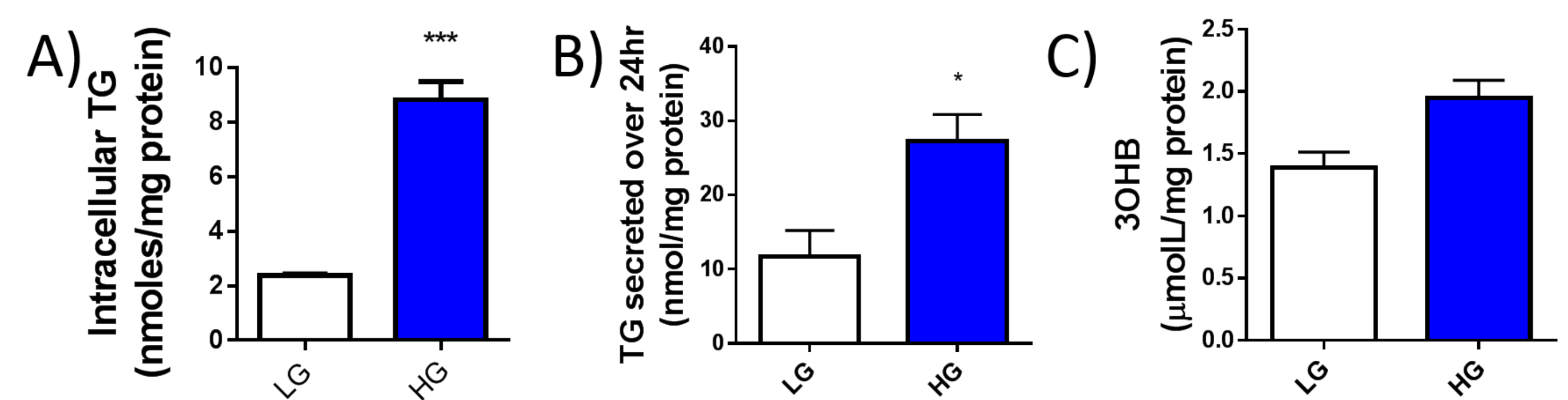

D)

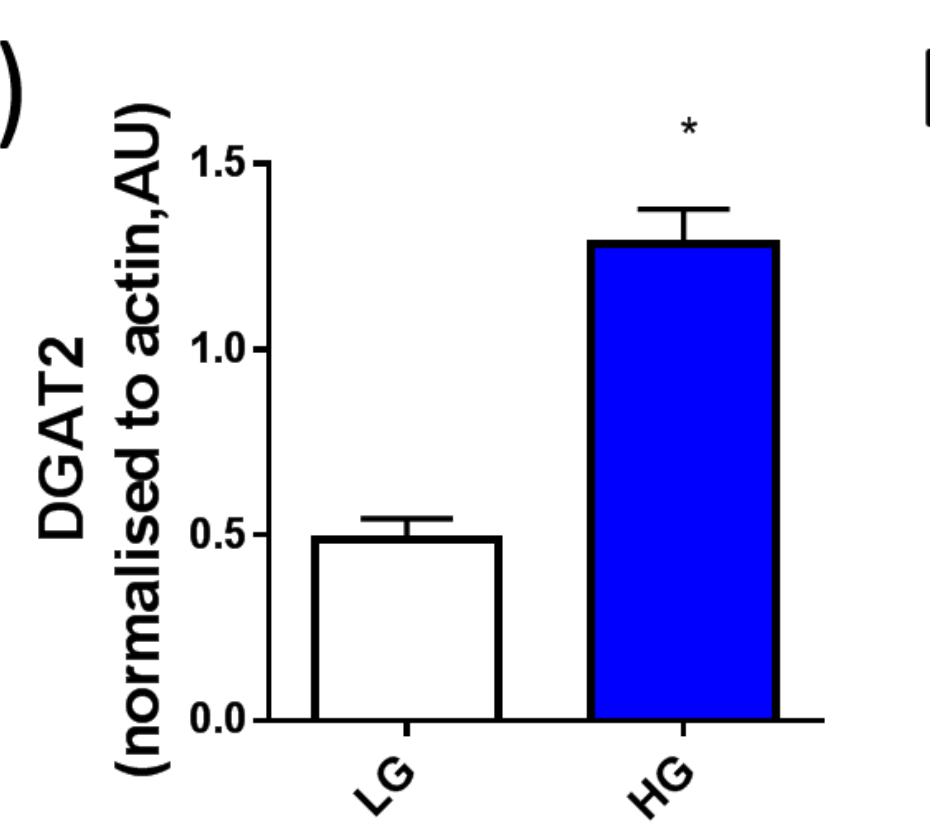

E) $\widehat{S}$
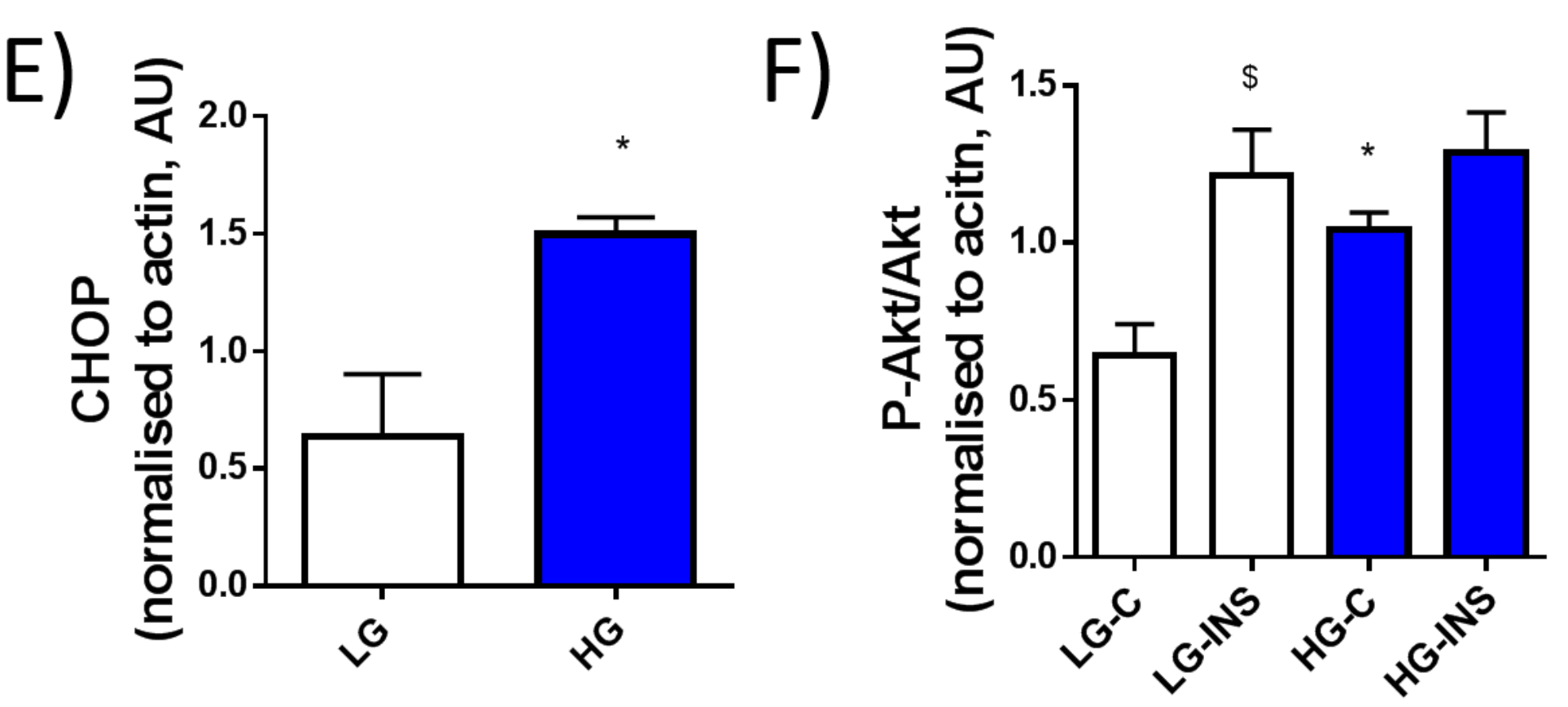

A) Effect of high glucose (HG, 22.5mM) on LIVOAPOLY cells. LIVOAPOLY cells treated with either LG or HG for 48h A) intracellular TG storage, B) secreted TG into media over 24h, C) appearenace of 3hydroxybytarte (3OHB) in the media, D) DGAT2 protein expression, E) CHOP protein expression. hydroxybytarte (3OHB) in the media, D) DGAT2 protein expression, E) CHOP protein expression.
LIVOAPOLY cells treated with either LG or HG for $48 \mathrm{~h}$ in the absence or presence of $100 \mathrm{nM}$ insulin $(10 \mathrm{~min})$ F) protein phosphorylation of Akt (S473). ${ }^{*} P<0.05 \mathrm{LG}$ vs HG, ${ }^{* * *} P<0.001 . \$ P<0.05 \mathrm{C}$ vs Ins.

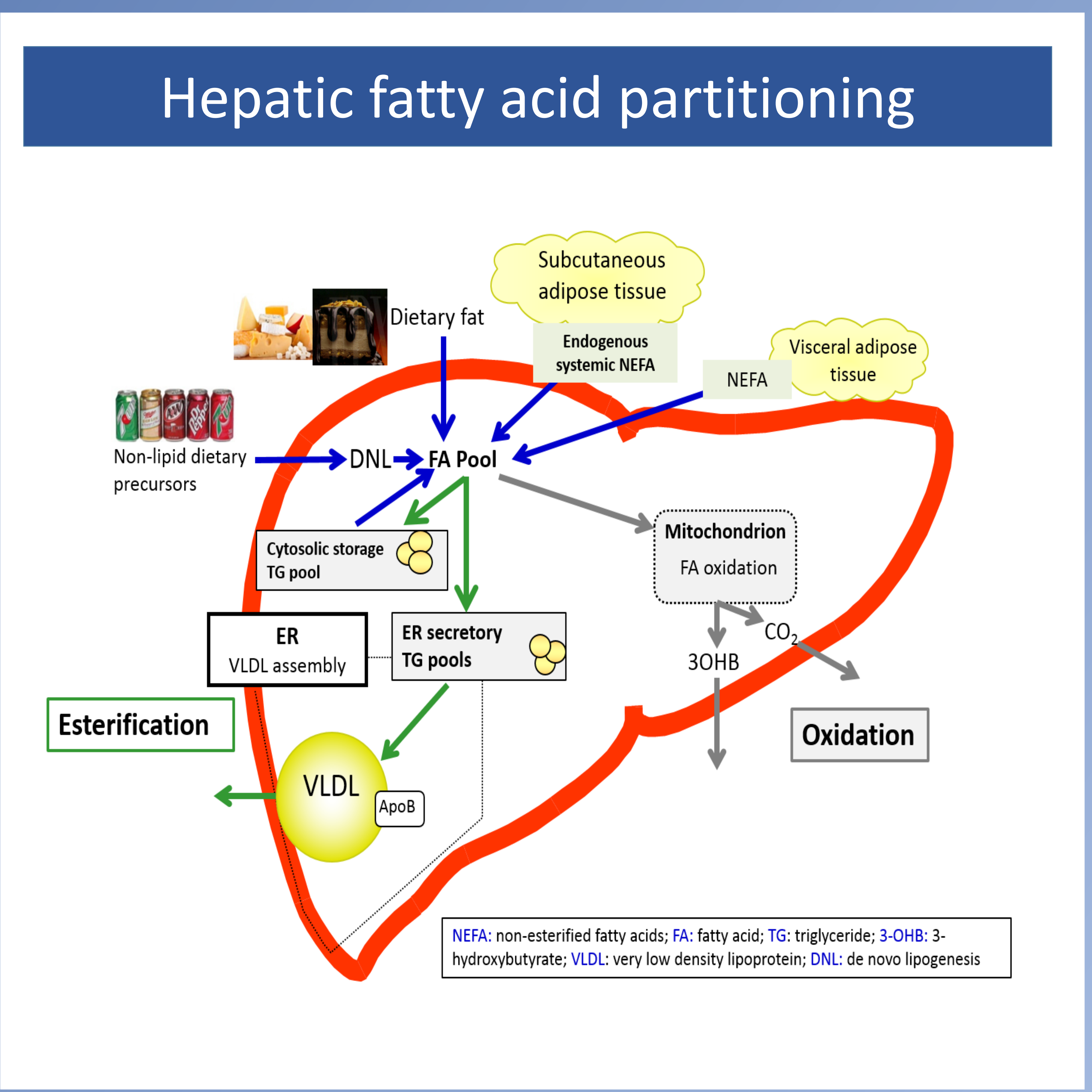

LIVOAPOLY cells effects of exogenous substrates on lipid partitioning

A)

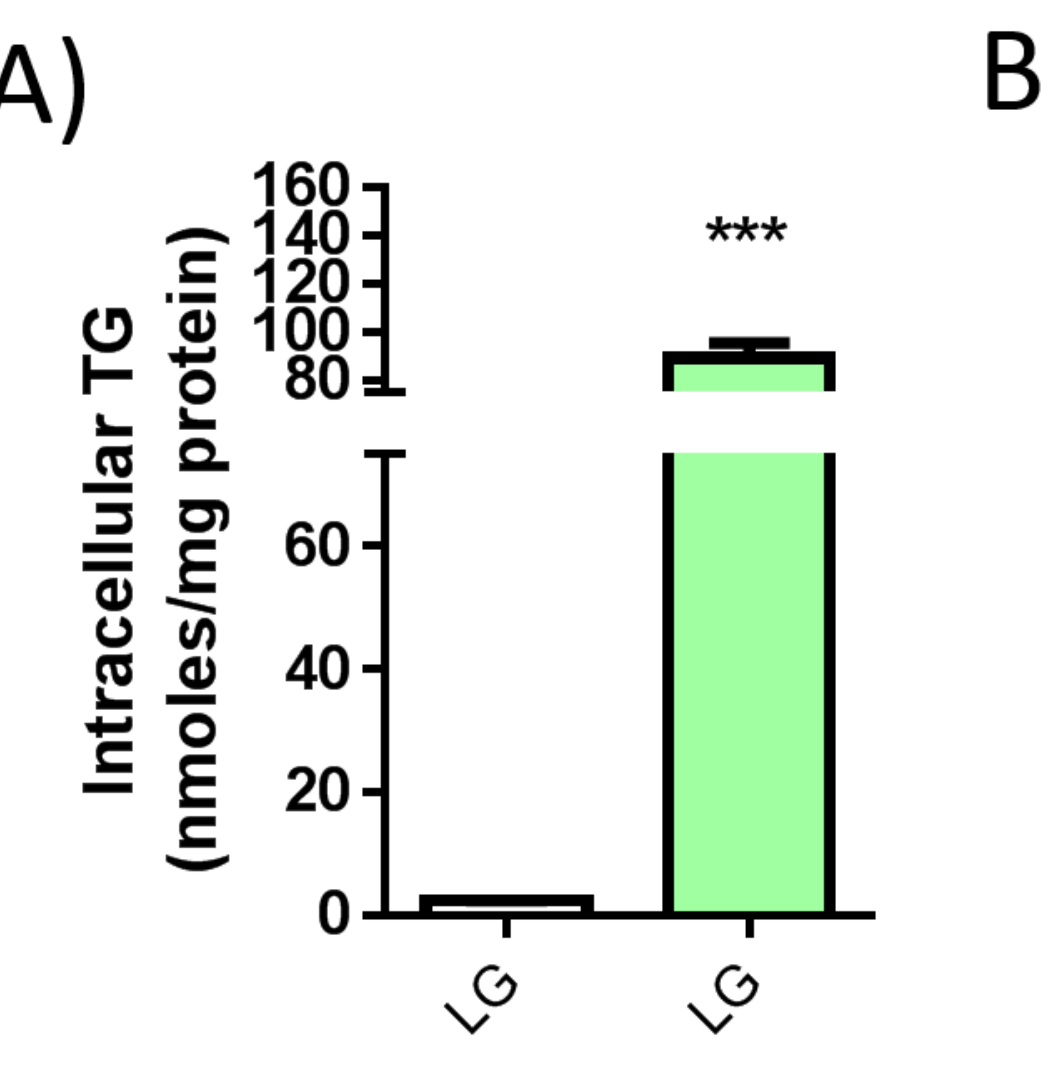

C) $\square$ HepG2

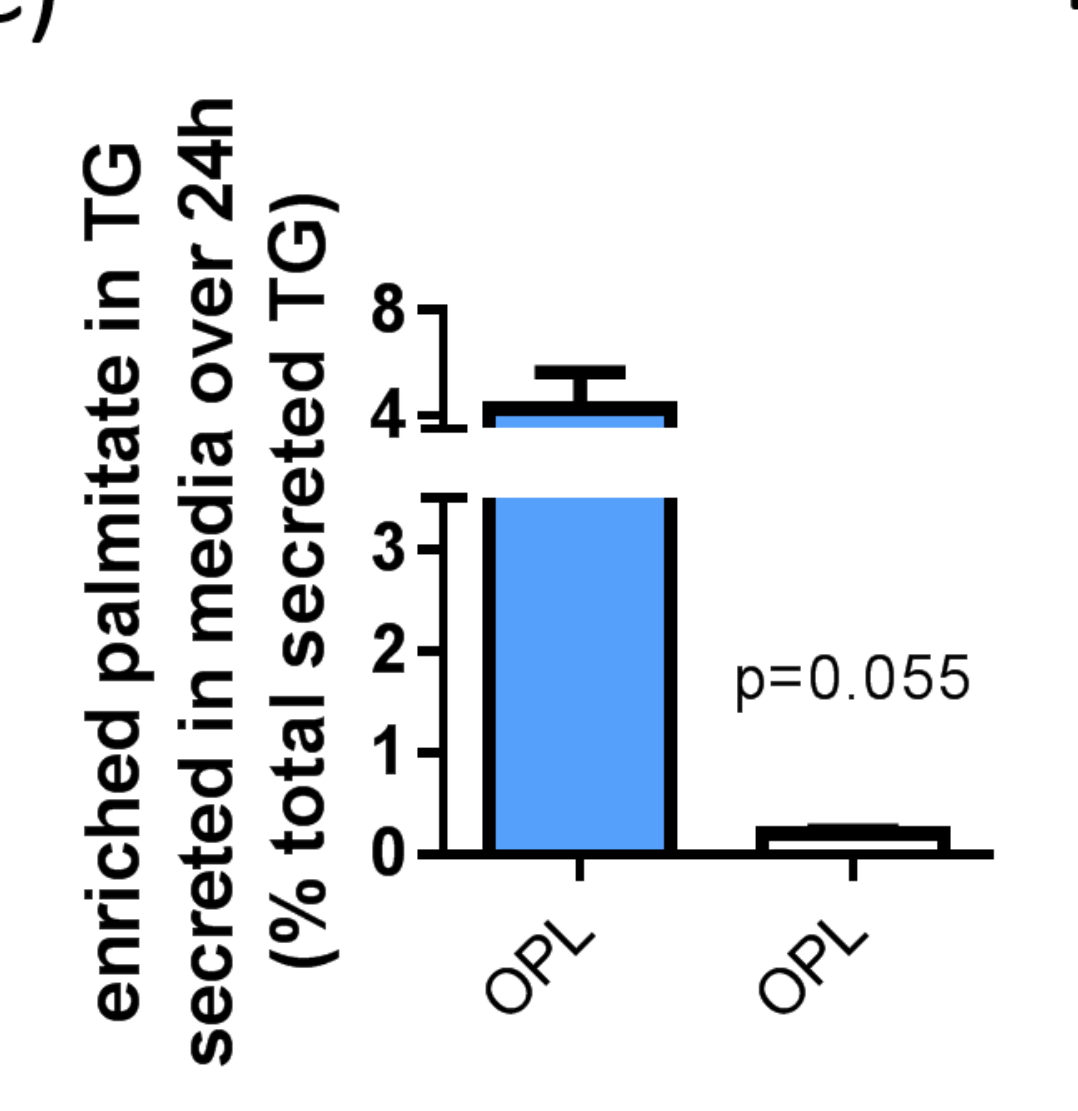

B)

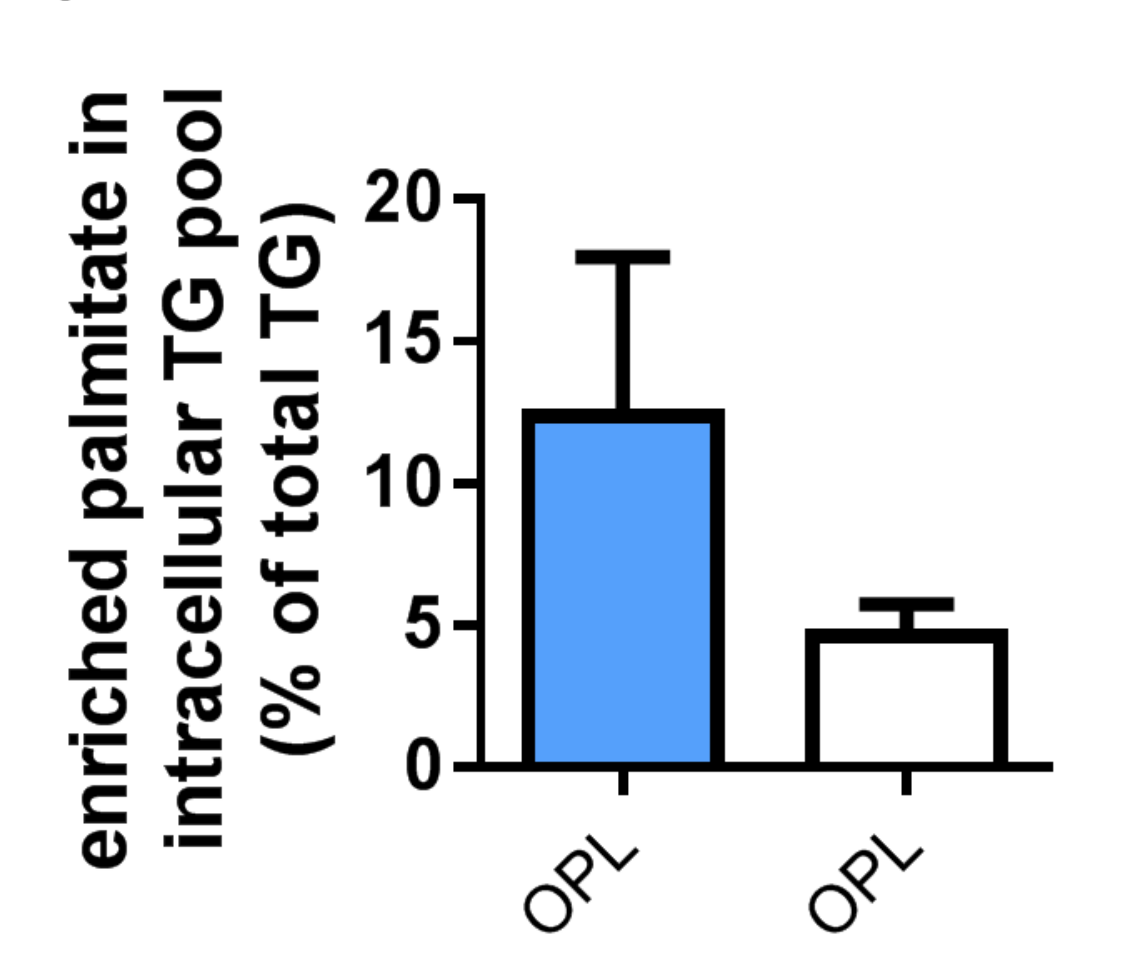

D) $\square$ Primary

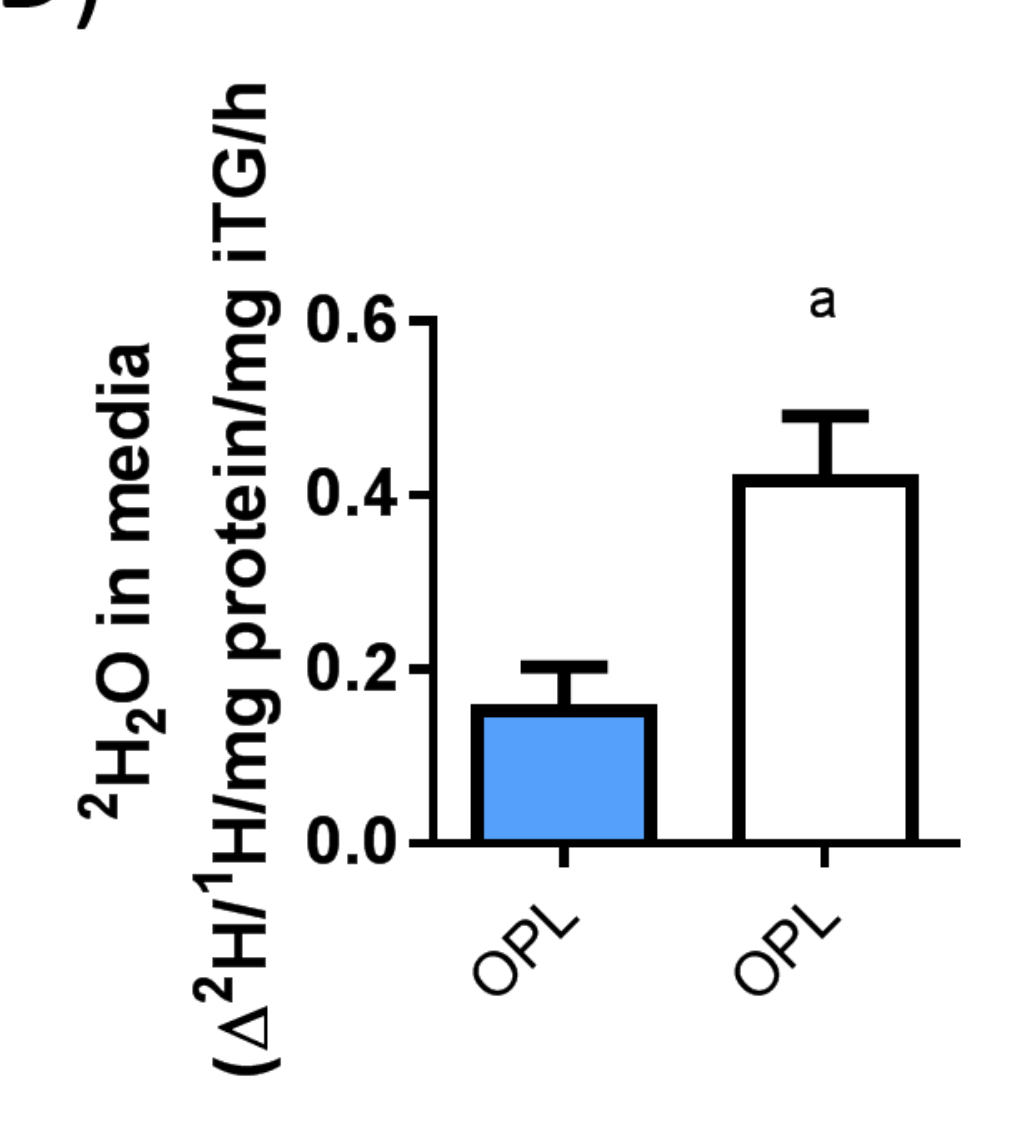

A) Effect of PNPLA3 rs738409 genotype on TG contents of LIVOAPOLY (wt/wt) and HepG2 (mut/mut) cells cultured unde low glucose (LG, $5.5 \mathrm{mM}$ ) conditions for $24 \mathrm{~h}(n=3)$. Data are means $\pm \mathrm{SE} . * * * P<0.001$ LIVOAPOLY vs. HepG2 cells. Fatty acid partitioning in LIVOAPOLY (5.5 mM glucose) and human primary hepatocytes (11mM glucose) cultured in the absence or labelled [either $\mathrm{D}_{31}$ or $\mathrm{U}^{13} \mathrm{C}$ ] almitate. B) percentage of palmich $B$ percentage of enriched palmitate in intracellular TG pool, C) in secreted $T G$ and $D$ ) quantification of ${ }^{2} \mathrm{H}_{2} \mathrm{O}$ in media as a marker of TG

oxidation. ${ }^{a} P<0.05$ primary human hepatocytes vs. LIVOAPOLY cells.

\section{Conclusions}

- LIVOAPOLY cells represent a human liver cell line that can be used to investigate lipid partitioning independently of genotype.

- Culturing liver cells in high glucose $(22.5 \mathrm{mM})$ promotes ER stress, steatosis and insulin resistance.

Funding:

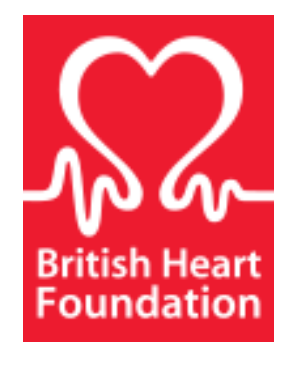

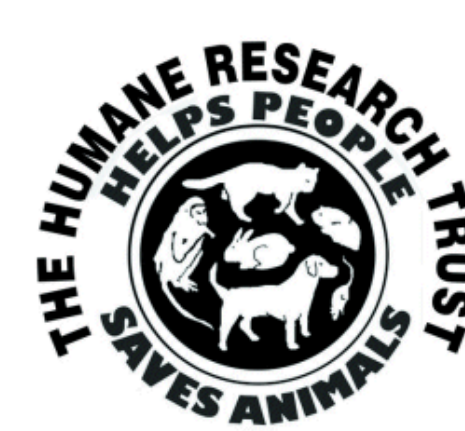

Download article: Green, C.J, AJP Endo, 2015 